\title{
IMMUNE STATUS OF HEALTH CARE PERSONNEL FROM VARIOUS GEOGRAPHICAL AREAS IN INDIA AGAINST RUBELLA: A CROSS- SECTIONAL STUDY
}

S. Sangeetha, P. Seema

1. Professor \& Head. Department of Microbiology, Rajarajeswari Medical College, Bangalore

2. Associate Professor. Department of Community Medicine, Rajarajeswari Medical College, Bangalore

\section{CORRESPONDING AUTHOR}

Dr. Sangeetha. S.

No. 684, BHEL L/O Extension, Pattanagere,

Bangalore -560098 .

E-mail: sangsampath@gmail.com

Ph: 00919743196662

ABSTRACT: Rubella is a mild illness that presents with fever and rash with the infection occurring sub clinically. Its public health importance is due to its teratogenic effects on the growing foetus in the first trimester of pregnancy. There is insufficient data in India with regard to rubella virus immunity in the community. Occupational exposure of health care personnel to rubella infection disease requires special attention. Hence this study was taken up to analyse the rubella seroprevalence rate according to age, geographical distribution, socio-economic class among health care personnel. Study design: Cross-sectional study. Methodology: 161 subjects aged between 15 to 30 years were given background information about the study and those who provided voluntary and written consent were enrolled. Study was conducted in the month of August 2010.Analysis of rubella specific IgG and IgM antibodies was done by ELISA. Results: Among 161 subjects, 88 subjects were from South India, 42 from North India, 19 from Eastern region and 12 were from the western region of India. Serum IgG positivity was the highest $100 \%$ in subjects hailing from Western India, followed by $84.2 \%$ from Eastern India and 83.3\% in subjects from north India. Subjects from South India showed the lowest seropositivity of $68.18 \%$. Conclusion: Immunisation of health care personnel against rubella and whole population of India for rubella immunity is necessary.

KEY WORDS: Rubella, immune status, health care personnel, India, serosurveillance MESH TERMS: Rubella, Immune status, Health Care Personnel, India

INTRODUCTION: Rubella is a mild viral disease with worldwide distribution. Several seroepidemiological studies for rubella antibodies have shown that a substantial number of women reach child bearing age without acquiring natural immunity to rubella ${ }^{1}$. Rubella is a mild illness that presents with fever and rash. In two-thirds of these cases, the infection occurs at a subclinical level${ }^{1}$. However the public health importance of rubella relates to teratogenic effects when infection is acquired in the early months of pregnancy². Occupational exposure among health care personnel is another factor that increases the chances of contracting rubella infection ${ }^{3}$.

India is a vast country but only few such surveys have been conducted so far. Data regarding rubella seroprevalence rate analysed according to age, geographical distribution, socio-economic class and previous history of immunization is not available. It was therefore considered worthwhile to conduct a study to obtain this data. 
MATERIAL AND METHODS: A cross-sectional study was conducted on 161 healthy subjects from the heterogeneous student population of our institute hailing from various geographical areas and socio-economic status in India after obtaining ethical clearance from Institutional Ethical Committee. 111(70.25\%) were MBBS students, 22(13.92\%) were nursing students, 9(5.69\%) BDS students, 8(5.06\%) lab technicians, 3(5.03\%) DMLT students, 2(1.26\%) doctors, and $1(0.63 \%)$ was a lab attendant.

$5 \mathrm{ml}$ of venous blood sample was collected after taking voluntary informed consent to determine whether rubella virus circulation in Indian population induces detectable IgG antibodies with a protective level in a random group of health care personnel.

Rubella specific IgG antibodies were detected using a commercial IgG enzyme linked immunosorbent assay (ELISA) Rubella IgG \& IgM Kit (Ani Biotech Oy, Orgenium Laboratories, Vantaa, Finland) in accordance with manufacturer's instructions.

All subjects were informed about the results. Seronegative subjects were counselled, and were advised to undergo vaccination with RA $27 / 3$ vaccine.

RESULTS: Table 1 shows the distribution of 161 health care professionals according to their age and sex. Most of the subjects, $114(70.8 \%)$ belonged to the $15-20$ year age group, $42(26.08 \%)$ to the $21-25$ age group and $4(2.48 \%)$ to the $26-30$ year age group. The mean age group was 22.5 years.

Among 161 subjects, 88 subjects were from South India, 42 from North India, 19 from Eastern region and 12 were from the western regions of India.

Majority of the subjects belonged to upper socio-economic status. Satisfactory vaccination history could not be obtained from most of the subjects as they could not remember their vaccination schedule.

Figure 1 shows seropositive and negative status of subjects from different regions of India. Serum IgG positivity was the highest $100 \%$ in subjects hailing from Western India followed by $84.2 \%$ from Eastern India and $83.3 \%$ in subjects from north India. Subjects from South India showed the lowest seropositivity of $68.18 \%$. All subjects were negative for serum IgM antibodies.

DISCUSSION: In our study we found a considerable variation in the prevalence of rubella antibodies among the health care personnel from various regions in India. Personnel from Western India showed the highest level of immunity (100\%) against Rubella, followed by $84.2 \%$ from eastern India, 83.3\% from north India and 68.18\% among South India. This is probably due to the differences in the dynamics of the development of natural immunity and immunity acquired through vaccination.

A study done by Seth etalin eastern India showed $56.8 \%$ of women in Calcutta had rubella antibodies 4 .There is no data available from western India.

Results of our subjects from north India had $83.3 \%$ seropositivity. However data among health care personnel is lacking from this region although, outbreaks have been reported 5 . Chitra Valsan et al have demonstrated $66.2 \%$ seropositivity in health care workers from Kerala, South India 6 . This is similar to our findings of $68.13 \%$ seropositivity.

CONCLUSION AND RECOMMENDATIONS: In the present study done on a heterogeneous population to determine the prevalence of rubella, seropositivity was $100 \%$ in western India, $84.2 \%$ in eastern India, $83.3 \%$ in north India with South India showing the lowest of $68.18 \%$. As 
there are very few studies from various regions of India, further studies are recommended. The results highlight the importance of immunisation among hospital personnel and eventual vaccination of the whole population in India.

LIMITATION OF THE STUDY: Small sample size was a limitation of this study. Further multi regional studies with a larger sample size are required in India.

ACKNOWLEDGEMENT: The authors would like to thank Mr. Girish of Standard Diagnostics, India Ltd for providing the ELISA kits for this study.

\section{REFERENCES:}

1. BERNARD N FIELDS; DAVID M KNIPE; PETER M HOWLEYet al; Field's Virology. Publisher: Philadelphia: Wolters Kluwer Health/Lippincott Williams \& Wilkins, 2007. $5^{\text {th }}$ Ed, Pg 548.

2. ROBERTSON SE, FEATHERSTONE DA, GACIC-DOBO M, HERSH BS. Rubella and congenital rubella syndrome: Global update. Pan Am J Public Health 2003; 14: 306-15.

3. SINGLA N, JINDAL N, AGARWAL A. The seroepidemiology of rubella in Amritsar (Punjab). Indian J Med Microbiol2004; 22: 61-3.

4. SETH P, MANJUNATH N, BALAYA S. Rubella infection: the Indian scene.Rev Infect Dis. 1985 Mar-Apr; 7 Suppl 1:S64-7.

5. MINI P. SINGH, KAVITA DIDDI, SUNIL DOGRA, VIKAS SURI, SUBHASH VARMA, RADHA K. RATHO - Institutional outbreak of rubella in a healthcare center in Chandigarh, North India.Journal of Medical Virology; Volume 82, Issue 2, pages 341-344, February 2010.

6. C.VALSAN, T.RAO, S.INNAH \& P.RAJI. Prevalence of Rubella immunity in health care students. The Internet Journal of Infectious Diseases. 2009 Volume 7 Number 2.

Table 1 shows age and sex distribution of health care personnel

\begin{tabular}{|l|l|}
\hline Age (Years) & No (\%) \\
\hline $15-20$ & $114(70.80)$ \\
\hline $21-25$ & $42(26.08)$ \\
\hline $26-30$ & $4(2.48)$ \\
\hline Total & 161 \\
\hline Sex & \\
\hline Male & $55(34.16)$ \\
\hline Female & $106(65.83)$ \\
\hline Total & $\mathbf{1 6 1}$ \\
\hline
\end{tabular}


Fig 1 shows region wise distribution of subject with their immune status against rubella

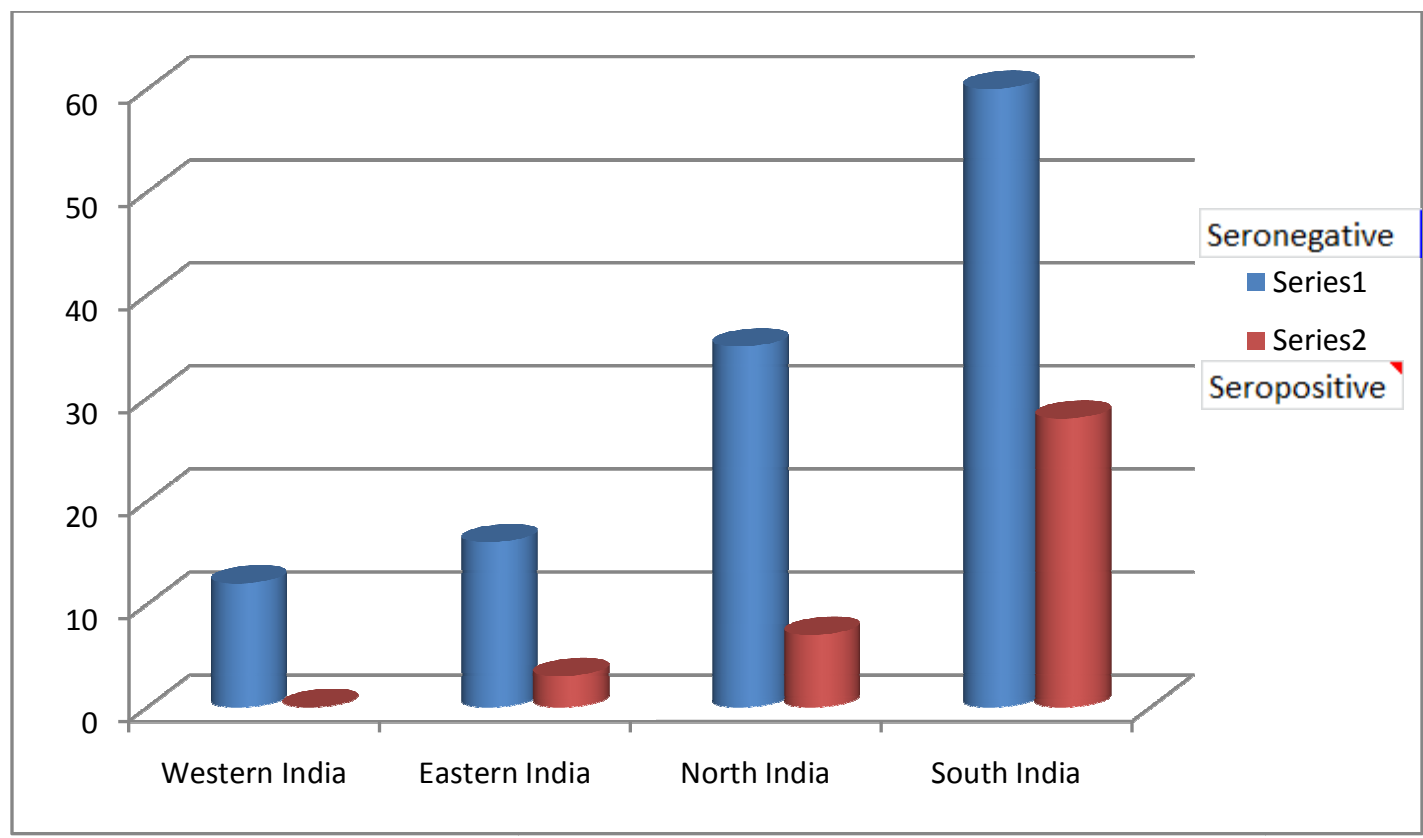

